\title{
EVALUATION OF SOIL-WATER RATIO EFFECTIVENESS IN SOIL-BATH WET SEPARATION PROCESS FOR KERNEL RECOVERY
}

\author{
C. P. Nwadinobi \\ Department of Mechanical Engineering, Abia State University, Uturu, Abia State, Nigeria. \\ E-mail address: chibundop@gmail.com
}

\begin{abstract}
An appraisal of the soil-water bath (wet separation) method showed that the method is based on the difference in density/specific gravity of the palm kernels and the shells. In this study, the separation of palm kernel-shell mixture using separating agent other than clay soil (kaolin) in wet separation have been considered. Measured masses of soil were added incrementally into $40 \mathrm{~L}$ of water and its density calculated and recorded. The separation efficiency of an alternative medium (laterite) was compared with that of clay soil (kaolin). Different mass quantities of kernel/shell mixture were poured into the red mud soil (laterite) slurry, and stirred. The part of Kernel/shell mixture that floated were scooped off and the Kernel selected and weighed. From observations made, the density/specific gravity increases with increase in mass of separating agent in water. The separating efficiency increased with increased soil input, till the $18 \mathrm{~kg}$ mark of soil input for both separating agents, when the floated kernel weight begins to be constant and highest. The optimal separation efficiency was found at medium/water ratio of 0.45:1. The effectiveness of the red mud (laterite) sample was found to be comparable to clay (kaolin) at a medium-to-water ratio of 0.45:1 giving 98.93\% efficiency. Thus, it is recommended to be used as an alternative to clay for wet separation.
\end{abstract}

Keywords: Oil Palm Kernel, Kernel Shell, Wet Separation, Clay Soil, Red mud.

\section{INTRODUCTION}

The oil palm (Elaesis guineensis) remains a great economic asset that a people can possess. The fruit, is a rich source of two distinct types of oil (the red palm oil and the palm kernel oil) which are used for various domestic and industrial applications. The red palm oil is obtained from the fibrous mesocarp of the fruit, while the palm kernel oil is obtained from the endosperm (palm kernel) which is tightly embedded in the hard endocarp (palm nut). According to Rohaya et al [1] both oils are mainly triglycerides but have difference in chemical and physical properties. To this end, palm oil have high palmitic acid $\left(C_{16}\right.$ fatty acid) while palm kernel oil is rich in both lauric and myristic acids $\left(\mathrm{C}_{12}\right.$ and $\mathrm{C}_{14}$ fatty acids respectively). Palm kernel oil is very valuable because it contains lauric acid, which is a useful fatty acid and a valuable raw material in the food and oleo-chemical industries and a major trade commodity in both local and international markets $[2,3]$. The production and processing of oil palm fruits remain a predominant enterprise among farmers in the oil palm producing areas of Nigeria.

In developing countries, palm kernel industry has high presence because of the dependence of many chemical industries on palm kernel oil as raw material $[4,5]$. According to Owolarafe et al. [6], about $90 \%$ of annual palm oil production in Nigeria generates palm kernel for palm kernel oil extraction. Palm kernel oil is used for the making of soap, detergents, vegetable oil, cosmetics and oleo chemicals [7]. Processing of palm kernels into palm kernel oil involves the cracking of palm nuts, separation of the palm kernel shells from the cracked mixture (Kernels and Shells), washing, cleaning, crushing and the extraction of palm kernel oil. Due to the high demand by the chemical industries for palm kernel oil as raw material, an efficient palm kernel cracking and 
separation method has become very important. The separation of palm kernel and shell mixture has remained a major problem militating against high production of palm kernel to meet industrial demand [8, 9].

Palm kernel-shell separation is an important aspect of palm kernel oil extraction process. Presently, the broad techniques employed in the separation of the mixture are the wet or dry method or a combination of both. Dry separation involves the use of no liquid medium rather, it uses difference in shape to achieve separation. On the other hand, wet separation is done in a liquid medium based on the difference in density/specific gravities of the constituents (the kernel and the shell) [10]. In specifics, several methods of palm kernel-shell separation are used by palm kernel processing industries (small, medium and large scale); they include traditional hand picking method, clay-water bath (kaolin), mechanical, pneumatic and Hydrocyclone methods. The claywater bath and the hydro cyclone are two separation methods based on density and are known as wet method since water is always involved. The relative density/specific gravity of palm kernel is about 1.1 and that of the shell ranges from 1.20 to 1.30 respectively [11 - 13]. For the wet separation method, the kernel recovered from the wet systems must be sterilized (dried) against the growth of moulds and redried for 14-16 hrs to remove moisture absorbed during the separation process [14 - 16].

Separation of palm kernel-shell cracked mixture have remained a challenging process especially to the small-scale mill owners [17]. Ronald [18] have attributed the poor efficiency in the clay-water bath separation method to the sub optimal ratio of water and kaolin for an optimal separation. Hence, in practice, trial and error methods are used. Often this results to efficient separation. Imbalance in the water and kaolin ratio is probably responsible for the sinking of some kernels along with the shells thus reducing separation efficiency. Other constraint include scarcity of the kaolin.

Furthermore, about $80 \%$ of oil palm processing in Nigeria is carried out by small scale processors [19]. Therefore, considering the enormous challenges confronting these small and medium scale palm kernel processors in separating cracked kernels from the shells, that usually employ the clay-water bath method, there is the need to appraise the efficiencies of the different separating soil materials that can be used. Again, it is important to estimate the optimal soil-water ratio to ensure good and effective separation. Therefore this study is aimed at investigating and evaluating the viability of red mud soil (laterite) as a separating agent in the wet method (the traditional soil-water bath separation process) on palm kernels and shells separation. This is aimed at achieving optimal separation ratio and also to undertake a comparative assessment of the separation efficiency of the test sample (red mud soil) with that of clay soil (kaolin) in wet separation.

\section{MATERIALS AND METHODS}

The uncracked palm nuts used for this appraisal were sourced from an oil palm processing centre located in Umuagungolori Afugiri village in Umuahia North L.G. A. of Abia State. The major materials utilized for this study are soil samples (clay (kaolin) and red mud soil), cracked kernels and shells mixture, water, weighing balance, scooper and stirrer. When the cracked mixture is admitted into the soil-water bath, the denser shells will sink to the bottom while the less dense kernels floats.

Machine cracked kernel-shell mixture were sifted in a sifter of $220 \mu \mathrm{m}$ mesh size and winnowed to remove debris from the mixture. Different soil sample masses were prepared for the separation process. In this process, the soil samples $\left(m_{s}\right)$ were tied in nylon bags and weighed using a weighing balance. For each soil sample used, different masses weighed out are dissolved into constant volume of water (40 litres) at each round. The 40 liters of water was kept constant and the soil sample weight ranged from $1 \mathrm{~kg}-30 \mathrm{~kg}$.

Ten kilograms $(10 \mathrm{~kg})$ of kernel-shell mixture was poured into a soil-water bath. The kernel-shell mixture was stirred, as the density difference makes the shells to sink and the kernel to float. The scooping of floating kernels is carried out followed by the washing and then sun-drying. The weights of the recovered kernels from the two soil samples were determined and used to calculate the separation efficiency and soil-water ratio of each mixture sample. In addition, the sunk shells were collected, washed, dried and weighed. This procedure is repeated for 18 samples of each soil sample.

\subsection{Determination of separation efficiency:}

The efficiency of the separation method was determined by determining the weight of the cracked kernel-shell mixture that was feed into the separation medium. The total weight of the kernel recovered at 
the end of separation process was measured. The separation efficiency was calculated by using the equation below;

$$
\text { separation efficiency }(\eta)=\frac{n_{\text {out }}}{n_{\text {in }}} \times 100
$$

where: $n_{\text {out }}$ - quantity of kernels recovered after separation; $n_{\text {in }}$ - quantity of cracked kernel/shell mixture that was feed into the separation medium.

\subsection{Determination of Shell Recovery:}

Weight of separated kernels $\left(W_{2}\right)$ obtained from each of the separation medium used. The shell, fibre and any other impurity $\left(W_{3}\right)$ were separated from each set of the samples and weighed.

The percentage shell and fibre was then calculated as follows;

$$
\text { shell/fibre recovery }(s f r)=\frac{W_{3}-W_{1}}{W_{2}} \times 100
$$

where:

$W_{3}$ is the weight of shell and fibre and the weighing container; $W_{1}$ is the weight of empty weighing container and $\mathrm{W}_{2}$ is the weight of separated kernels.

\section{RESULTS AND DISCUSSIONS}

Results obtained showed that small quantity of kernel and shell floated on the water sample without the addition of soil material. This phenomenon can be attributed to the difference in specific gravities/ densities of these constituent materials. Water has a specific gravity/density of 1.0 , the specific gravity of kernel is 1.10 while that of the shell ranges between 1.20 to 1.30. On addition of soil material to the water, the kernel and shell mixture keeps separating. From Table 1, it was observed that the specific gravity/density of the soil-water solution keeps increasing with the continuous addition of the soil sample; the quantity of the floating kernel mass increases. It was also observed that as the red mud (laterite) sample is continually added, it reached a level where a constant floating mass of kernel was always recorded.

In addition, it was observed that as the soil content increases, the rate of kernel recovery increases. This trend continues until a level is attained where the floating mass of kernel became constant after each soil addition. This therefore gave an indication that the soil-water bath solution is fully saturated and cannot perform further separation.

The result of the experiment presented in Table 2, shows that kernel recovery increases with increase in clay soil content in the soil-water bath solution. It was also observed that the maximum kernel recovery was obtained at $18 \mathrm{~kg}$ clay soil content in 40 liters of water.

Table 1: Red mud soil System Performance Result, (kernel-shell

\begin{tabular}{|c|c|c|c|}
\hline $\begin{array}{l}\text { Experimental } \\
\text { runs }\end{array}$ & $\begin{array}{l}\text { Red mud } \\
(\mathrm{kg})\end{array}$ & $\begin{array}{l}\text { Kernel (nut) } \\
\text { recovery (kg) }\end{array}$ & $\begin{array}{l}\text { Shell and dirty } \\
(\mathrm{kg})\end{array}$ \\
\hline 1 & 1 & 0.02 & 9.98 \\
\hline 2 & 2 & 0.04 & 9.96 \\
\hline 3 & 3 & 0.06 & 9.94 \\
\hline 4 & 4 & 0.6 & 9.4 \\
\hline 5 & 5 & 0.8 & 9.2 \\
\hline 6 & 6 & 1 & 9 \\
\hline 7 & 8 & 1.5 & 8.5 \\
\hline 8 & 10 & 2.5 & 7.5 \\
\hline 9 & 12 & 2.6 & 7.4 \\
\hline 10 & 14 & 2.8 & 7.2 \\
\hline 11 & 16 & 3 & 7 \\
\hline 12 & 18 & 3.2 & 6.8 \\
\hline 13 & 20 & 3 & 7 \\
\hline 14 & 22 & 2.9 & 7.1 \\
\hline 15 & 24 & 3 & 7 \\
\hline 16 & 26 & 3 & 7 \\
\hline 17 & 28 & 3 & 7 \\
\hline 18 & 30 & 3 & 7 \\
\hline
\end{tabular}
mixture $=10 \mathrm{~kg}$ and water $=40$ liters

Table 2: Clay soil (Kaolin) System Performance Result (kernelshell mixture $=10 \mathrm{~kg}$ and water $=40$ liters

\begin{tabular}{llll}
\hline $\begin{array}{l}\text { Experimental } \\
\text { runs }\end{array}$ & $\begin{array}{l}\text { Clay } \\
(\mathrm{kg})\end{array}$ & $\begin{array}{l}\text { Kernel } \\
\text { recovery }(\mathrm{kg})\end{array}$ & $\begin{array}{l}\text { Shell and dirty } \\
(\mathrm{kg})\end{array}$ \\
\hline 1 & 1 & 0.03 & 9.97 \\
2 & 2 & 0.06 & 9.94 \\
3 & 3 & 0.12 & 9.88 \\
4 & 4 & 0.7 & 9.3 \\
5 & 5 & 1 & 9 \\
6 & 6 & 1.3 & 8.7 \\
7 & 8 & 1.7 & 8.3 \\
8 & 10 & 2.5 & 7.5 \\
9 & 12 & 2.7 & 7.3 \\
10 & 14 & 2.95 & 7.05 \\
11 & 16 & 3 & 7 \\
12 & 18 & 3.18 & 6.82 \\
13 & 20 & 3.01 & 6.99 \\
14 & 22 & 2.93 & 7.07 \\
15 & 24 & 3.04 & 6.96 \\
16 & 26 & 2.97 & 7.03 \\
17 & 28 & 3.02 & 6.98 \\
18 & 30 & 3 & 7 \\
\hline
\end{tabular}


It was observed that on the addition of clay increases the specific gravity/density of the fluid. This increment in specific gravity/density brings about an increment in the rate of kernel recovery. This is because the kernel being less dense than the shell, floats on the solution while the shell settles at the base of the separating container. This trend continues till the maximum kernel recovery point of separation is attained. At this maximum separation point, there is no floating shell(s) accompanying the floating mass of kernels. After this point, it was observed that with further increase in clay content in the soil-water solution there was no more proportional increase in floated kernel mass. Rather, the floating kernel mass remained relatively constant afterwards.

\section{CONCLUSION}

This study investigated the efficiency of oil palm kernels and shells separation using red mud (laterite) as a possible substitute and comparing the separation efficiency with that of clay soil (kaolin). In addition, the effect of soil-water ratio (soil sample: water) and sample separation efficiency were evaluated. Experimental results showed that the suitable separating condition (of kernel and shell) was achieved at $18 \mathrm{~kg}$ of soil sample in 40 liters of water. At these conditions, average kernel recovery of $98 \%$ was achieved with both soil samples (red mud and clay (kaolin)). From the results obtained, it is evident that separation efficiency increases with increase in specific gravity/density of the separation media.

Generally, from the conducted experiments and analysis of the results, it can be concluded that for separation of the palm kernel and shell mixture to occur, the density of the separation medium (soilwater solution) must be greater than the density of the kernel but less than the density of the shell. When the density of the separation medium is increased above the density of the shell, the shell floats in this case. Therefore, to have an optimal separation, the density of the separation medium should be higher than that of the kernel but less than that of the shell. From the findings of this study, it is recommended that red mud soil can be used as a veritable substitute to clay soil in the soil-water wet separation method of palm kernel-shell mixture. This is because the method is relatively cheap with high separation efficiency. It is also suitable for rural environment where most local farmers/processors are located.

\section{REFERENCES}

[1] Rohaya, M. H., Ridzuan, R., Che, R. C. M., Choo, Y. M., Nasrin, A., Numan, A. Dry separation of palm kernel and palm shell using a novel fivestage winnowing column system Technologies, 4 (13). 2016.

[2] Pantzaris, T. P. Pocketbook of palm oil uses. $5^{\text {th }}$ Edition. MPOB Bangi; pp. 102-109. 2000.

[3] Gbadam, E. K., Anthony, S., Asian, E. K. Determination of some parameters for palm nut cracker. European Journal of scientific Research, 38 (2): pp. 315-327. 2009.

[14] Akubuo, C. O. and Eje, B. E. Postharvest technology: Palm kernel and shell separator; Biosystem Engineering, 81(2); pp. 193-199. 2002.

[5] Oke P. K. Development and Performance Evaluation of Indigenous Palm Kernel Dual Processing Machine, Journal of Engineering and Applied Sciences, Medwell Journal. 2007.

[6] Owolarafe, O. K., Sanni, I. A., Edinowe, O. S., Oginyomi O. T. and Faborode, M. O. Development of an oil palm fruit stripper. Journal of Agricultural Engineering and Technology, 10: pp. 59-64. 2002.

[7] Akusu O. M, Kiin-Kabari D. B and Barber L. I Palm Kernel Separation Efficiency And Kernel Quality From Different Methods Used In Some Communities In Rivers State, Nigeria, Journal of Food Technology Research, Vol.4, No. 2, pp. 4653. 2017.

[8] Akubuo, C. and Eke, J. Palm kernel/shell separator. Mechanical Engineering Department, University of Nigeria, Nsukka, pp. 1-3. 2009.

[9] Adewale, O. and Olufermi, K. A rotary separator for the dry mixture of palm kernel and shell. Innovative Systems Design and Engineering, 5(7), pp. 32-42. 2014.

[10] Lateef A. S., Taiwo O. and Raifu O. I. Saline Bath System for Separation of Palm Kernels from Shells, International Journal of Agricultural and Biosystems Engineering. Vol. 2, No. 6, pp. 67-73, 2017.

[11] Fono Toma and Koya O. A. Characterization of Pulverized Palm Kernel Shell for Sustainable Waste Diversification; International Journal of Scientific and Engineering Research; Vol. 4, Issue 4, pp. 6-10. 2013. 
[12] Hartley, C. W. S. The Project of Oil Palm and the Extraction in the Oil Palm, London: Longman Publishers, pp. 40-48. 1987.

[13] Agu R. S., Eze P. C. and Omeje C. U. Separation of Oil Palm Kernel and Shell Mixture Using Soil and Palm Ash Slurries, Nigerian Journal of Technology (NIJOTECH), Vol. 36, No. 2, April 2017, pp. 621 - 627. 2017.

[14] Nasser, M. S. and James, A.E. Settling and Sediment Bed Behaviour of kaolinite in Aqueous Media. Separation and Purification Technology, 51: pp. 10-17. 2005.

[15] Amoah, J. Y., Aggey, M., and Annumu, S. Cracked- Mixture Sieving Rates and Efficiencies In Small Scale Palm Nut Processing In Ghana, Ghana Journal of Science. 44 (1) pp. 103-105. 2007.

[16] Adewale O. and Olufemi K. Experimental Verification of a New Technique for the Dry
Separation of Palm Kernel and Shell Mixture; Innovative Systems Design and Engineering, Vol.4, No.14, pp. 27-33. 2013.

[17] Kamalu, C. I. O., Nwaigwe, K. N. and Nwakaudu, M. S. Manipulation of Slurry Density of Red Mud Clay in the Separation of Fine/Coarse Palm Kernel Shell, Research Journal of Mathematics and Statistics 7(3): pp. 27-32. 2015.

[18] Ronald, A. A. J. Separation optimization of palm kernel by its specific gravity and flow rate of clary water bath. Unpublished B.Sc. Degree Project, Faculty of Chemical and Natural Resources Engineering, Universiti Malaysia Pahang. 2012.

[19] Kwasi and Poku, K. Traditional Techniques and Innovations in Small Scale Palm Oil Processing; Retrieved Oct 03, 2010, From FAO Agricultural Services Bulletin. 2002. 